\title{
Infrared detection of codling moth larvae in apples
}

\author{
R.T. Wilkinson ${ }^{1}$, L.E. Jamieson ${ }^{1}$, A.J. Hawthorne ${ }^{1}$, D.E. Hartnett ${ }^{1}$, N.E.M. Page-Weir ${ }^{1}$, G. Kaunds ${ }^{2}$ and \\ P. Lindegger ${ }^{2}$
}

${ }^{1}$ The New Zealand Institute for Plant \& Food Research Limited, PO Box 92169 Mt Albert, Auckland
${ }^{2}$ Compac Sorting Equipment Limited, PO Box 13516, Onehunga, Auckland, 1643
Corresponding author: reuben.wilkinson@plantandfood.co.nz

Codling moth, Cydia pomonella (Lepidoptera: Tortricidae), is a key pest of apples exported from New Zealand and is difficult to control at levels required to ensure quarantine security demanded by many countries. Market access for New Zealand apples into countries with strict codling-moth quarantine regulations currently relies on methyl bromide fumigation combined with cold treatment (e.g. Japan) or the use of a rigorous systems approach (e.g. Taiwan). Detection of codling moth in apples would enable the very few apples in the packhouse with codling moth to be graded out. In this study, a commercially available Compac Spectrim grading system was used to determine if codling moth entry holes could be detected. This system provides high-clarity images through enhanced lighting and optics, as well as using various infrared wavelengths to target different defects and machine-learning algorithms to differentiate defects. Apples infested with first- or third-instar codling moth larvae were processed through the Spectrim machine. The system successfully identified 100\% of apples infested with firstinstar larvae and $96 \%$ of apples infested with third-instar larvae. Additionally, damage caused by the two life stages was able to be differentiated.

\section{Performance attributes of an unmanned aerial vehicle (UAV) configured for aerial pesticide application operations}

\author{
B. Richardson ${ }^{1}$, S.F. Gous ${ }^{2}$, W.C. Schou ${ }^{1}$, T.M. Strand ${ }^{1}$ and L.A.H. Wright ${ }^{1}$ \\ ${ }^{1}$ Scion, Private Bag 3020, Rotorua 3046, New Zealand \\ ${ }^{2}$ HeliResources, PO Box 407, Rotorua 3040, New Zealand \\ Corresponding author: brian.richardson@scionresearch.com
}

There is worldwide interest in the use of unmanned aerial vehicles (UAVs) or drones for a wide range of purposes. One area of focus relevant to New Zealand is use of UAVs as aerial platforms for pesticide spray operations. While not yet in common use in New Zealand, there are many potential areas of application for this type of technology including small scale pest eradication operations in urban environments as part of biosecurity responses, treatment of widespread wilding conifers with herbicides, and small-scale pest management operations in a range of productive sector environments. One example of the latter currently being investigated is application of herbicide to compartment edges in forestry situations where the lower release height compared with a helicopter could significantly reduce spray drift. This poster summarises early results from studies to quantify some performance attributes of a UAV configured for both biosecurity and conventional spray operations. Swath patterns were measured from a UAV configured with a range of nozzle types and under various operating conditions. From these data, potential work rates were calculated for different application scenarios. 